\title{
Access Denied: Academic Life Under Lockdown
}

\author{
Nesta Devine $^{1} \cdot$ Georgina Stewart $^{1} \cdot$ Leon Benade $^{1}$
}

Published online: 28 April 2020

(c) New Zealand Association for Research in Education 2020

Our university has cancelled normal classes and meetings for the rest of 2020, with all teaching and learning moving to an emergency online form of delivery-a direction each of the other universities of Aotearoa New Zealand will surely follow, in part at least. Our swipe cards have been deactivated for an initial period of 4 weeks, taking in the planned 2-week mid-semester break, denying us access to our offices and campuses. Our Facebook feeds consider the question of productivity for an academic under lockdown; an email update on the situation helpfully suggests making use of all this time at home to 'get on with our research'. We know we are incredibly privileged to be among the few in our communities who can continue to work at all, and go on being paid as normal.

The Covid-19 pandemic is a circuit-breaker at every level, from the personal to the local, institutional, national, and global. The pandemic is pedagogical; it is a lesson or test for humanity. It makes us look again at everything we thought was important: it is not only a medical but also an existential crisis, a crossroads, a crack in the facade of 'reality' that underpins the system we have been calling 'business as usual'. The variation in response seen in different 'Western' countries provides evidence of the differing philosophies on which they are based: the stark choice between people and profit laid bare, the emptiness of neoliberal rhetoric now becoming embarrassingly apparent. The UK PM, who boasted in early March of visiting hospitals and shaking hands with infected people, is now in ICU, ill with the virus for nearly a fortnight. Lack of preparedness and an initially laissez-faire approach have precipitated a terrible demonstration, still unfolding at the time of writing (April 2020), of the limits of 'American exceptionalism' (Levitz 2019).

Even here in Aotearoa New Zealand, where the measures of border control, testing and tracing, and a general 'stay at home' 28-day period seem to have prevented the exponential growth phase of the epidemic, commentators representing business and right-wing politics are calling for the lockdown to be lifted early, since it has 'worked,' and, in the same breath, accusing the government of recklessly damaging the country's businesses and economy. It appears the UK and US initially considered allowing the infection to take its course in the population under the belief that it

Leon Benade

leon.w.benade@aut.ac.nz

1 Auckland University of Technology, Auckland, New Zealand 
would quickly become less virulent, and the community would develop natural herd immunity, as happens for the host of viruses with which humans already cope, with sick and old people being the most affected. This kind of thinking was predicted long ago by Jonathon Swift in his satirical 'modest proposal' that babies born to impoverished families could be the basis of a useful edible product for consumption by the wealthy (Swift 1995).

The existential crisis caused by the pandemic results from the abrupt and major disruption to our normal ways of social functioning, as well as the psychological and social impacts of not only what is happening, but also the fear of the unknown in an unprecedented situation for all of us. It is also a crisis for education: how can teaching and learning proceed as normal in such an abnormal world? Presence is fundamental to the interpersonal relationships that underpin education, and which cannot be replaced by use of technology. Yet, if we have always accepted correspondence and home schooling as viable alternatives for families under certain circumstances, such as living in remote locations or as a matter of political/religious preference, there is a logical argument that such arrangements could feasibly become the "new normal' of schooling.

The prevailing economistic form of bureaucratic rationality under which we operate makes it more difficult to 'think' the pandemic. The neoliberal tendency towards 'presentism' engenders an amnesia that denies access to history for explaining the reasons for current conditions. But the expansion of economistic thinking to the entire planetary system, on which the current form of neoliberalism is based, also denies access to modes of thought that would prepare for possible futures (such as so-called 'black swan' events), based on realistic estimations of human behaviour and motivation. 'Access denied' refers to the denial of the full spectrum of human cognition and creativity in the genres and frameworks available to scholars and thinkers of all stripes, under globalised neoliberal policy conditions.

International cooperation and good science averted the worst effects of SARS, MERS and Ebola, and the expectation seems to have been that this would happen again. 'Presentism', which supports the contemporary focus on short-term profits, exacerbated by accounting practices, electoral cycles, even newspaper deadlines, ignores the long-term, historical effects of major events like the current pandemic. The Black Death of the fourteenth century had huge economic results, effectively ending the feudal system in much of Europe. There had been cracks in the system beforehand, but the Black Death, by altering the relationship between employer and labourer, speeded its uneven demise. Although serfdom did not cease in Russia until the nineteenth century, through most of Western Europe, the financial relationships between aristocracy and labourer were forever altered. What analogous results might arise from this pandemic? Will the social and financial status of frontline essential workers through the pandemic - nurses, health assistants, grocery workers-be improved?

The immediate result of the Black Death was a savage endeavour on the part of local lords to reimpose their will and privilege over their serfs and villeins, which proved fruitless in the face of the new disposition of the workforce. Will we experience something similar to this reaction? Is the now widespread acceptance of the role of technology and its accompanying surveillance a likely outcome of this 
experience? What will be the spatial effects of 'stay in place'? Will we head towards some kind of intellectual cottage industries, somewhat like the early industrial revolution, with the computer replacing the spinning wheel, as big employers such as universities see the possibility of not providing space or equipment to white collar workers?

A favourite story from the Black Death is that of the village of Eyam, a tiny spot in Derbyshire, which locked itself up when it found the plague in its midst, in order to prevent spreading it to neighbouring villages. Eyam paid a huge toll itself, but won the eternal gratitude of its neighbours - and, incidentally, made a living for itself centuries later, by capitalising on the tourists fascinated by its history. It seems Aotearoa New Zealand could become the Eyam of the twenty-first century, but by providing an example of good leadership and effective use of science and scientists, rather than by sacrificing itself. This exemplary pandemic response in itself is a tribute to the quality of our education system that has evolved over the last 200 years. We have an educated population, despite the presence of a few 'idiots' — and an educated leadership. Our ability to pull together is a priceless result.

\section{References}

Levitz, E. (2019, 2 January). American exceptionalism is a dangerous myth. Retrieved from https:// nymag.com/intelligencer/2019/01/american-exceptionalism-is-a-dangerous-myth.html

Swift, J. (1995). A modest proposal for preventing the children of poor people from being a burthen to their parents or country, and for making them beneficial to the public. Child Youth Care Forum, 24(5). https://doi.org/10.1e007/BF02125026 (original work published 1720)

Publisher's Note Springer Nature remains neutral with regard to jurisdictional claims in published maps and institutional affiliations. 